\title{
CASE OF TABES DORSALIS.
}

BY J. MICHELL CLARKE, M.A., M.B., M.R.C.P.,

Assistant Lecturer on Physiology, Bristol Medical School; Assistant Plysician Gencral Hospital.

In the following case of Tabes Dorsalis, the presence of nystagmus, the persistence in some degree of the knee-jerks, and the predominance of symptoms in the upper extremities afford unusual features in the course of this disease. The patient, a warehouseman, aged fifty-three, first came ander my observation on October 15th, 1888, and has been constantly under my care since. Except that his mother suffered from asthma, that two brothers died in infancy, and that one sister has dropsy of cardiac origin, his family history gave us no information. No member of his family had ever suffered from any nervous disease, nor from gout nor rheumatism, his grandparents on both sides dying at an advanced age. He had always been very healthy until four years previously, when he had a severe fall, breaking bis right leg. To this fall he attributes his illness, as he says, that "it shook his nerves all over." He is a very temperate man, and has never had syphilis.

Careful enquiry, however, elicited that for a year before the fall he had suffered from burning pains in the arms and hands, and this must be therefore regarded as the first symptom of the disease, the course of which was probably accelerated by the accident. After the injury he suffered from general weakness and numbness of arms and legs, with well marked girdle pain, and "rheumatic gout" in right great toe joint, and from shooting pains in arms and legs, followed by a feeling as if cold water was being poured over him. For two years he had been giddy, especially in the dark, with a tendency to fall on closing his eyes; for past ten months there had been diplopia. He had not had attacks of palpitation, nor of sickness; micturition was normally performed; habitual constipation ; sexual power good.

On examination he is a tall man, and looks older than his years. His gait is feeble and uncertain rather than ataxic, when he tries to walk with his eyes closed he is very unsteady, and there is then some ataxy of movement. He is unable to turn 
round quickly without catching hold of something to steady himself. He cannot stand steadily with his feet placed together, and Romberg's symptom is well marked.

At this date there was decided want of co-ordination of the movements of the hands and arms with loss of the sense of posture, and of the power of distinguishing between different weights; the inco-ordination increased when the eyes were closed. He bad lost the power of writing from inability to hold and direct the pen properly. Sensation to pain, touch and temperature normal, or perhaps slightly deficient. The muscles are rather flabby and weak.

In the legs sensation and muscular sense quite normal; the muscles firm and of good size showed no wasting nor increase of the direct muscular irritability. When lying on the couch he could move his legs freely without ataxy whether the eyes were open or shut. No rigidity of muscles, which everywhere react normally to both kinds of electric current. The right knee-jerk was generally absent, but could sometimes be obtained, the left knee-jerk present but feeble, and could be brought out well by causing him to perform some muscular action, such as hitting out with the left arm, at the same time that the tendon was struck.

The right big toe joint was enlarged, with much bony thickening, and the joint loose and grating, the proper extensor tendon tense, so that the first phalanx was over-extended on the meta tarsal bone, the head of the latter being pushed downwards. In the absence of any family history or personal evidence of gout this was taken to be a tabetic arthropathy. In the eyes there was paralysis of the right external rectus; when the eye was moved into the inner canthus it oscillated, i.e., was jerked two or three times towards the left before remaining steady. The pupils were unequal, the right larger than the left, both acted to accommodation, neither dilated on sensory stimulus to skin of neck, the right was motionless to light, the left acting feebly. No paralysis of any other cranial nerve. Dynamometer gave 30 with right hand, 28 with left.

On one occasion whilst being examined he had a well-marked laryngeal crisis, and during the winter 1888-89 several severe gastric crises. Under the usual treatment, at first with arsenic and iodide of potash, and later with cod-liver oil, quinine, nuxvomica, \&c., his symptoms grew steadily worse. From April to November suspension was tried, and was carried out more or less regularly three times a week throughout this period. On account of a tendency to syncope he was never suspended for more than 
$1 \frac{1}{8}$ to 2 minutes at a time. The effect of suspension was seen in marked improvement as regards the legs, he was able to walk more strongly and steadily and for greater distances, the giddiness decreased and he no longer complained of giddiness in the dark; at the end of the time he could stand steadily with the feet together and the eyes closed for five minutes. Since the suspension he has been able to walk about easily, and for considerable distances at a time, and has lost completely the lightning pains in the legs, so that the general effect as regards the legs was very satisfactory. On the other hand the arms grew steadily worse, and he suffered from frequent and severe gastric crises, one lasting for ten days, during which he was exceedingly ill and very weak for some time afterwards. In October, 1889, he had intense burning pains in the arms and severe girdle pain, and in November suspension was left off as the treatment seemed to have accomplished its beneficial action on the leg symptom and not to have affected the arms at all, at any rate in the direction of improvement. Distinct loss of sensation other than subjective feelings of numbness came on in the hands and arms during the summer of 1889 , and in November tactile sensation was lost over the right hand, and was very deficient and perverted to temperature (cold objects felt as hot) and to pain. The same loss existed in less degree over the left hand, right forearm and back of left forearm. Except as regards the affection of the upper extremities, which has steadily but slowly increased, his state has remained about the same up to the present time. Lately the gastric crises have ceased, the girdle pain is slight and only occurs occasionally. On examination, February 6 th, 1891 , he complains chiefly of burning pains in the arms, which are intensified by touching any hot object.

Sensation in Upper Extremitics.-Over inner side of left arm. the two points of the æsthesiometer are distinguished at a distance of eleven centimetres from each other, but in no other part of arms, forearms, or hands can they be discriminated. A light touch is nowhere felt. Over the right hand he can just tell ice from nearly boiling water; over the arm on the same side sensation to temperature deficient only, but on right forearm and whole of left upper extremity no distinction between hot and cold can be made; cold is felt as hot. As regards pain, sensation is lost over palms and palmar aspects of fingers, and elsewhere is exceedingly defective in both limbs; it is most preserved in the right thumb. He is very slow or fails altogether to localise sensations, and their perception is much delayed. The sense of 
position of the limbs is entirely lost, so that without sight he cannot say in what position his arms lie. He cannot distinguish between the weight of a shilling and of three sovereigns piled one on the other. Coarse movements are periormed by the aid of sight, but very vaguely and imperfectly without it. Finer movements, such as picking up a small object, writing, or buttoning his waistcoat, are impossible. When he tries to slowly touch his nose with his forefinger, the movement is interrupted by ataxie jerkings, apparently with the object of preventing the too rapid movement of his arms. These jerkings sometimes give an appearance of coarse tremor to the movement, and when he holds out his hands, slow movements of extension and flexion of the fingers occur, which resemble athetosis, but are not rbythmic, and evidently result from involuntary irregular relaxations and contractions of the muscles. This may be compared with the great difficulty he has in relaxing a contracted nuscle at will. When he sits up and closes his eyes, some tremor of the head and neck becomes obvious.

The muscies generally are weak and flabby, with exaggerated idio-muscular irritability, the pectorals are rather small, and show very well the phenomenon of myoidema. On the other hand, all the tendon reflexes are absent.

Legs and Trunk.--Some defect of sensation to temperature over fcet and legs, over thighs and trunk normal; sensation to pain fair, to touch defective over lower extremities generally. Two points are felt as one over the soles of the feet; on the dorsum they are distinguished at a distance apart of 7-8 cc.; on the legs, outer side, 12; inner, $11 \mathrm{cc}$; thighs at $4-5 \mathrm{cc}$., and there is distinct delay in appreciating and localising a touch; over abdomen and back sensation normal, muscles of legs well nourished, movements strong, with little or no inco-ordination, and no loss of muscular sense. The right knee-jerk can occasionally be obtained, but is often absent; the left present, but weak, and can always be brought out if the patient performs a voluntary movement. Tickling the soles of the feet excites a contraction of the anterior muscles of the thigh. Cremasteric, gluteal and plantar reflexes normal. The muscles generally react too readily to percussion on their mass.

Mr. C. H. Walker, the ophthalmic surgeon to the Hospital, reports as the result of his examination of the eyes, that both pupils are slightly irregular in size and shape :-R. $5 \mathrm{~mm}$. diam.; L. $4.5 \mathrm{~mm}$. diam.; $\mathrm{R}$. hazel grey; L. hazel brown in colour. Neither act to accommodation. R., no reaction to light; $L$. acts 
to light fairly. In both eyes there is fine lateral nystagmus, which is not constant, but occurs from time to time, and is especially brought out after rotating the eyes several times laterally. There is occasional tremor of the orbicularis palpebrarum-most marked on the left side-coincident with the nystagmus. The left eye is on a somewhat higher level than the right-about $2 \mathrm{~mm}$. higher. The right external rectus is completely paralysed, with corresponding diplopia. The lenses show a few fine cortical opacities. The optic discs are not atrophied, and show no sign of past neuritis, though they are a little irregular in outline. Fields of vision almost normal. Myopic astigmatism of slight degree in both eyes.

The nystagmus was not present when the patient first came under observation; it was first noticed about eighteen months ago, but as stated above, the right eye from the first, when directed into the inner canthus showed two or three jerking movements before settling down. Possibly, the fine opacities in thelens, acting together, with imperfect co-ordination of the ocular anuscles, may account for it, just as nystagmus is often observed in young children who have had corneal opacities from an early age, before the centres for the movements of the eyeballs are fully organized. So that in this case I should conclude that the origin of the nystagmus lay in the imperfect impressions of the muscular sense, reaching the centres from the ocular muscles together with the presence of opacities on the lens. The movements consist of a very fine and rapid motion horizontally. 